\title{
Discrepancies in Written Versus Calculated Durations in Opioid Prescriptions: Pre-Post Study
}

Benjamin H Slovis ${ }^{1,2}$, MA, MD; John Kairys ${ }^{1,3}$, MD; Bracken Babula ${ }^{1,4}$, MD; Melanie Girondo ${ }^{5}$, RN, MSN; Cara Martino $^{5}$, RN, MSN; Lindsey M Roke ${ }^{5}$, PharmD; Jeffrey Riggio ${ }^{1,4}, \mathrm{MD}$

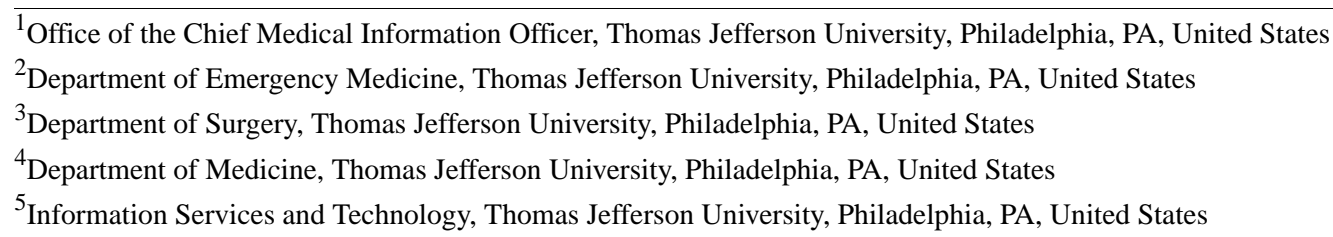

Corresponding Author:

Benjamin H Slovis, MA, MD

Office of the Chief Medical Information Officer

Thomas Jefferson University

833 Chestnut St, 10th Floor

Philadelphia, PA, 19107

United States

Phone: 12159557975

Email: Benjamin.Slovis@jefferson.edu

\section{Abstract}

Background: The United States is in the midst of an opioid epidemic. Long-term use of opioid medications is associated with an increased risk of dependence. The US Centers for Disease Control and Prevention makes specific recommendations regarding opioid prescribing, including that prescription quantities should not exceed the intended duration of treatment.

Objective: The purpose of this study was to determine if opioid prescription quantities written at our institution exceed intended duration of treatment and whether enhancements to our electronic health record system improved any discrepancies.

Methods: We examined the opioid prescriptions written at our institution for a 22-month period. We examined the duration of treatment documented in the prescription itself and calculated a duration based on the quantity of tablets and doses per day. We determined whether requiring documentation of the prescription duration affected these outcomes.

Results: We reviewed 72,314 opioid prescriptions, of which $16.96 \%$ had a calculated duration that was greater than what was documented in the prescription. Making the duration a required field significantly reduced this discrepancy $(17.95 \%$ vs $16.21 \%$, $P<.001)$ but did not eliminate it.

Conclusions: Health information technology vendors should develop tools that, by default, accurately represent prescription durations and/or modify doses and quantities dispensed based on provider-entered durations. This would potentially reduce unintended prolonged opioid use and reduce the potential for long-term dependence.

(JMIR Med Inform 2020;8(3):e16199) doi: $\underline{10.2196 / 16199}$

\section{KEYWORDS}

informatics; electronic health record; opioids; prescription; duration

\section{Introduction}

The United States is in the midst of an opioid epidemic [1,2].

The rate of death from opioids is increasing; more than $67 \%$ of the 70,237 overdose deaths in the United States in 2017 were attributed to opioid drugs [3]. Drug overdoses could soon become the number one cause of death of Americans under the

age of 50 years [4]. Opioid overdoses are a public health crisis associated with significant medical costs and resource utilization [5-11]. Chronic opioid use is often preceded by treatment of acute pain [12], and long-term prescription opioids are associated with progression to illicit opioid abuse [13]. Despite the clear correlation between prescription opioid use and mortality, opioids continue to be routinely prescribed [2,14,15]. While the United States makes up only $4.3 \%$ of the global 
population [16], Americans consume more than $80 \%$ of the world's supply of opioid medications [17].

In the Commonwealth of Pennsylvania, there were 5456 drug-related overdoses in 2017 [18], the third-highest of any state for drug-related deaths in the nation [19]. In 2016, 60\% of all Pennsylvania counties had prescribing rates higher than the national average. In 2017, even though there was an overall decline in opioid prescriptions, enough oxycodone and hydrocodone were dispensed to provide every Pennsylvanian with 32 dosage units of these drugs [18].

Reduction in the number of opioid prescriptions, opioid doses, and duration of treatment are critical to curbing the opioid epidemic. State prescription drug monitoring programs (PDMPs) allow physicians to assess a patient's controlled-substance prescription history [20]. Chronic opioid use and risk of death have been associated with higher prescription doses and longer durations [12,21]. After the third day of use in an opioid-naïve individual, the likelihood of chronic opioid use increases daily. This increase is most drastic on days 5 and 31 [22]. Therefore, the US Centers for Disease Control and Prevention (CDC) has authored guidelines on opioid dosing and duration for acute and chronic pain [23,24]. Specifically, they recommend a duration of 3 days or less for acute pain, and advise that more than 7 days is unlikely to be required. The $\mathrm{CDC}$ also recommends that prescriptions should be of no greater quantity than what is required for the duration of treatment [23]. Consequently, opioid prescriptions with unintentionally prolonged durations of treatment may result in increased risk of chronic opioid use and associated morbidity and mortality [25].

Health information technology can play a critical role in improving quality of care while improving guideline adherence and decreasing errors [26]. Electronic health records (EHRs) have been associated with advanced quality of patient care [27-29], and computerized provider order entry (CPOE) is associated with improved efficiency and safety [30]. CPOE can improve medication ordering through clinical decision support systems in both active (ie, a pop-up warning of drug-drug interactions) and passive (ie, a dose-appropriate default prescription setting) approaches [31]

Some health information technology interventions that require providers to review aspects of current or prior opioid prescriptions have been demonstrated to affect opioid prescribing patterns. For instance, PDMP mandates that require the review of controlled substance prescription history prior to and during opioid prescribing have demonstrated a reduction in opioid prescribing rates [32]. Additionally, while some hospitals have attempted to control opioid prescribing patterns through prescription presets of a specific number of tablets $[33,34]$, others have demonstrated both reductions and increases in tablets dispensed when requiring manual entry of number of tablets to dispense in a prescription $[35,36]$.

Our current vendor-based EHR's CPOE ordering screen has four fields for opioid prescription entry: (1) dose (ie, number of tablets), (2) frequency (eg, three times a day), (3) duration (ie, number of doses or days), and (4) quantity (ie, the number of tablets dispensed). Previously, the system did not auto-calculate duration from dose, frequency, and quantity or vice versa. Instead, it alerted the provider within the CPOE ordering screen and recommended updating the duration or quantity. This means a provider could write a prescription with a duration of 3 days and a quantity of 200 tablets with only a soft alert. Additionally, prior to August 2018, our institution did not require a duration value to be entered into our CPOE, meaning this field could be left blank. In August 2018, we introduced a number of interventions via modifications to our EHR's opioid prescription settings: (1) duration was set to be a required field, (2) a quick button for 3 days' duration was added to coincide with CDC guidelines for acute pain, and (3) tablet quantity for all opioid orders was preset to 10 .

The purpose of this research is to examine if there are differences between the duration of treatment as written in an opioid prescription versus the duration associated with the dosing frequency and number of pills dispensed. That is to say, we examined how long the number of dispensed pills at the prescribed frequency would last (ie, the calculated duration) and compared that to the duration documented by the prescriber (ie, the written duration) for opioids ordered by providers at our institution. Additionally, we examined whether the requirement of a value in the duration field-from the interventions described above-had any effect on accurately representing the calculated duration of the prescription. We take special interest in those durations that are calculated to be longer than what was written in the duration field, as these directly contradict the CDC prescribing guidelines [23] and may increase risk of the associated negative effects of prolonged opioid use.

\section{Methods}

\section{Data Acquisition}

We queried the EHR system of the Center City division of our health care system, which includes an urban academic tertiary care center, an urban academic community hospital, and multiple ambulatory clinics. We examined data generated by Epic (Epic Systems Corporation) via a third-party analytics software, Qlik Sense (QlikTech International), to develop a list of all outpatient opioid prescriptions, including discharge medications, written over 22 months from October 2017 to July 2019. This includes an 11-month preintervention period and an 11-month postintervention period.

We extracted a number of variables, including the quantity of tablets, the dosage units (ie, $\mathrm{mg}$ ), the route of administration (ie, oral vs buccal), the discrete dose (ie, $15 \mathrm{mg}$ vs $10-15 \mathrm{mg}$, based on the number of tablets per dose), the written duration, and the frequency of administration.

For the purposes of this study, we limited the route of administration to oral and excluded all nontablet formulations. Finally, we excluded the medications buprenorphine and methadone, as these are routinely used for the management of opioid use disorder.

\section{Calculated Duration}

In order to compute the calculated duration of each prescription, we took each of the unique possible frequencies in the system (ie, twice a day or every 4 hours) and mapped these to the 
equivalent number of administrations per 24-hour day. For pro re nata $(\mathrm{PRN})$ medications, we selected the maximum frequency possible. Therefore, "twice a day PRN" resulted in two daily administrations and "every other day" resulted in a daily administration of 0.5 .

Next, we took all doses that contained ranges for their discrete dose (ie, 20-30 mg) and isolated the maximum dose possible per administration (ie, $30 \mathrm{mg}$ ). We calculated the number of tablets per administration by dividing the maximum dose by the dose per tablet. We calculated the total number of possible doses by dividing the quantity dispensed by number of tablets per administration. Finally, we computed the calculated duration, measured in days, by dividing the total number of doses by the number of administrations per 24 hours. The choice of the maximum dose per administration means that our calculated duration is the shortest possible when holding the other variables constant.

\section{Statistical Analysis}

We first converted all written durations to be represented in units of days. We then examined the proportion of prescriptions that did not have a written duration to determine if our intervention had an effect on the documentation of this field.
We also examined the proportion of prescriptions for which we could not compute a calculated duration to ensure the preintervention and postintervention periods were similar. Finally, we compared the number of prescriptions written with ranges (ie, 20-30 mg) to see if our intervention had an effect on this category of prescriptions.

To compare what was documented (ie, written duration) to what was dispensed (ie, calculated duration) for each prescription, we then generated our study cohort by excluding any prescription that did not hold a value for both of these fields. Also, since we computed the calculated duration in units of days, we excluded all written durations not also documented in units of days.

We examined the written duration of each prescription and compared it to the calculated duration. We categorized each relationship as a written duration equal to, greater than, or less than the calculated duration. We examined whether there were any changes in the relationships between written duration and calculated duration before and after our interventions, with specific interest regarding the requirement to document a written duration. See Table 1 for examples of each field and how we coded relationships.

Table 1. Examples of each field extracted from the electronic health record system, with written duration and calculated duration demonstrated, along with their relationship.

\begin{tabular}{|c|c|c|c|c|c|c|c|}
\hline Drug & Prescription instructions & $\begin{array}{l}\text { Dispense } \\
\text { quantity }\end{array}$ & $\begin{array}{l}\text { Written } \\
\text { duration }\end{array}$ & $\begin{array}{l}\text { Administrations } \\
\text { per day }\end{array}$ & $\begin{array}{l}\text { Maximum dose per } \\
\text { administration }\end{array}$ & $\begin{array}{l}\text { Calculated } \\
\text { duration }^{\mathrm{a}}\end{array}$ & Relationship \\
\hline $\begin{array}{l}\text { Morphine: } \\
15 \mathrm{mg} \\
\text { tablets }\end{array}$ & $\begin{array}{l}\text { Take } 1-2 \text { tablets as needed } \\
\text { twice a day for } 3 \text { days }\end{array}$ & 12 & 3 days & 2 & $30 \mathrm{mg}$ (2 tablets) & 3 days & $\begin{array}{l}\text { Written duration is } \\
\text { equal to calculated } \\
\text { duration }\end{array}$ \\
\hline $\begin{array}{l}\text { Morphine: } \\
15 \mathrm{mg} \\
\text { tablets }\end{array}$ & $\begin{array}{l}\text { Take } 1-2 \text { tablets as needed } \\
\text { twice a day for } 3 \text { days }\end{array}$ & 8 & 3 days & 2 & $30 \mathrm{mg}$ (2 tablets) & 2 days & $\begin{array}{l}\text { Written duration is } \\
\text { longer than calculat- } \\
\text { ed duration }\end{array}$ \\
\hline $\begin{array}{l}\text { Morphine: } \\
15 \mathrm{mg} \\
\text { tablets }\end{array}$ & $\begin{array}{l}\text { Take } 1-2 \text { tablets as needed } \\
\text { twice a day for } 3 \text { days }\end{array}$ & 20 & 3 days & 2 & $30 \mathrm{mg}$ (2 tablets) & 5 days & $\begin{array}{l}\text { Written duration is } \\
\text { shorter than calculat- } \\
\text { ed duration }\end{array}$ \\
\hline
\end{tabular}

${ }^{\mathrm{a} C a l c u l a t e d}$ duration $=(($ quantity of tablets $\times$ drug dose in $\mathrm{mg}) /$ maximum dose per administration $) /$ administrations per day.

Data cleaning and calculations were performed in Qlik Sense. Statistical analysis was performed in the statistical software R, version 3.3.2 (The R Foundation). Chi-square analysis was used for categorical values. The $t$ test was used for parametric data and the Wilcoxon rank-sum test was used for nonparametric data.

\section{Results}

\section{General Results}

There were 92,462 unique opioid prescriptions that met initial inclusion criteria during our study period for 30,426 individual patients. There was a mean number of prescriptions per month of 4202.82 (SD 204.32) and a median number of prescriptions per person per month of 1 (IQR 1-2).

In the preintervention period, there were 47,131 prescriptions for 16,863 individual patients; in the postintervention period, there were 45,331 prescriptions for 17,483 individual patients.
There was no significant difference $(P=.06)$ between mean number of prescriptions per month in the preintervention period (mean 4284.64 [SD 200.68]) versus the postintervention period (mean 4121.00 [SD 180.74]). The median number of 1 prescription per person per month did not change (IQR 1-2, $P=.37)$.

There was a statistically significant decrease in the proportion of prescriptions with no written duration documented postintervention $(33.54 \%, 95 \%$ CI $33.12-33.97$, vs $9.45 \%, 95 \%$ CI 9.19-9.72, $P<.001$ ). Evaluation of the remaining $9.45 \%$ of prescriptions without a written duration appear to be due to refills of prior prescriptions, which were exempt from the new documentation requirement.

There was a small but significant difference in the proportion of prescriptions in which we were unable to compute the calculated duration when comparing the preperiod and the postperiod $(6.01 \%, 95 \%$ CI $5.80-6.23$, vs $3.61 \%$, 95\% CI $3.44-3.79, P<.001)$. 
There was no significant difference pre- and postintervention in the number of prescriptions that contained ranged doses (ie, $20-30 \mathrm{mg})(4.42 \%, 95 \%$ CI $4.23-4.61$, vs $4.66 \%$, $95 \%$ CI 4.47-4.86, $P=.08)$.

There were 72,364 out of 92,462 (78.26\%) total prescriptions that had a written duration documented. Of these, there were $2632(3.64 \%)$ prescriptions whose written duration units were converted from other duration units to days, while the rest were already written in this unit of measurement. Out of 72,364 prescriptions, $50(0.07 \%)$ were excluded because the calculated duration could not be computed. This resulted in 72,314 out of $92,462(78.21 \%)$ total prescriptions meeting the inclusion criteria for our comparison: out of 72,314 prescriptions, 31,300 $(43.28 \%)$ were in the preintervention period and 41,014 $(56.72 \%)$ were in the postintervention period. Figure 1 demonstrates the inclusion and exclusion criteria and separate cohorts for comparison.

Figure 1. Breakdown of cohorts based on inclusion and exclusion criteria and separation into preperiod and postperiod cohorts.

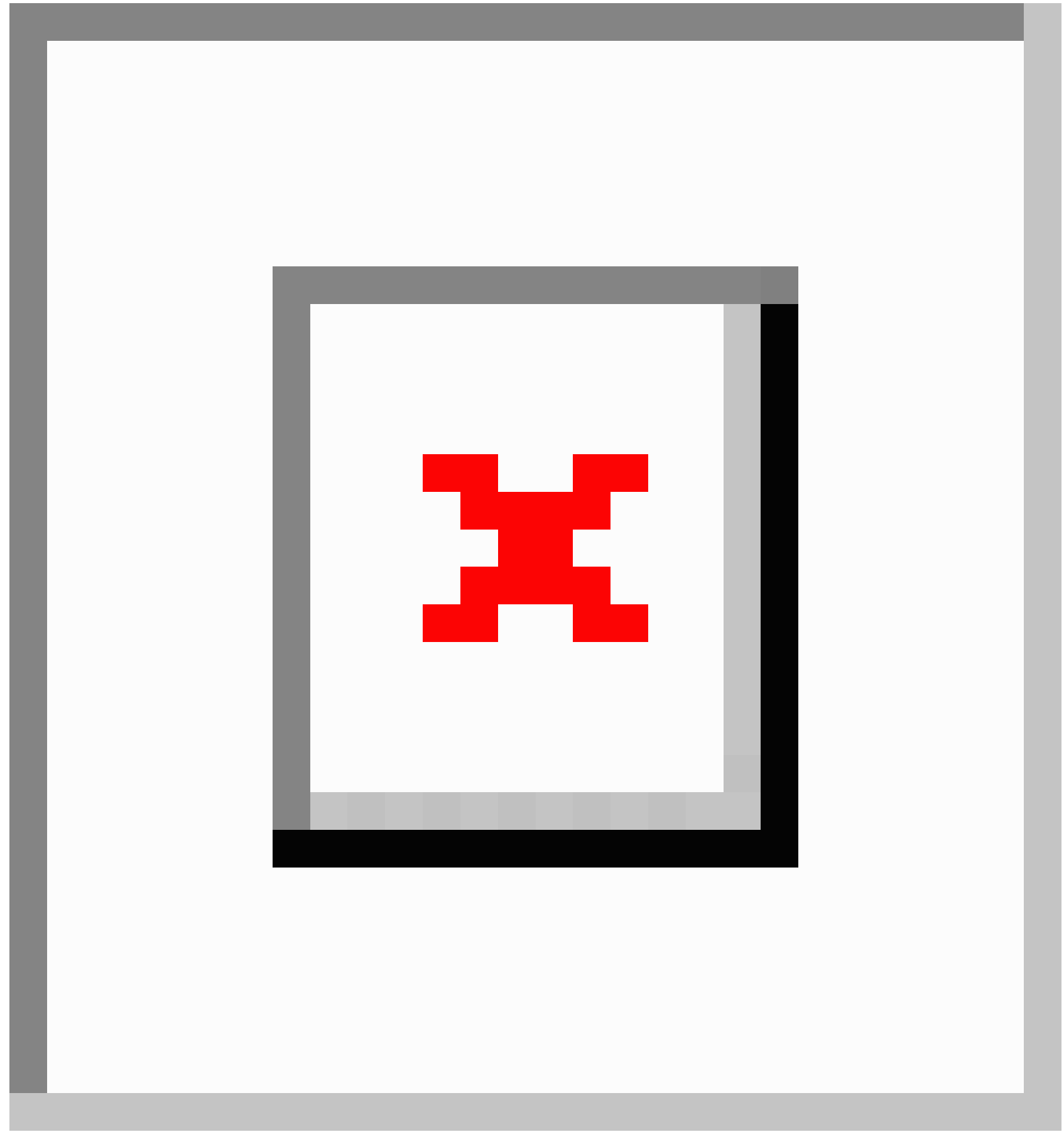

\section{Comparison of Written and Calculated Durations}

Of the 72,314 prescriptions, $41.97 \%$ (30,353 total, 95\% CI 41.61-42.33) had calculated durations that were equivalent to their written durations, $41.06 \%$ (29,694 total, 95\% CI
40.70-41.42) had calculated durations that were less than their written durations, and $16.96 \%(12,267$ total, 95\% CI 16.69-17.24) had a calculated duration that was greater than the written duration. 
Requiring a written duration to be documented significantly improved the number of calculated durations that were equal to their corresponding written duration, from $38.86 \%$ $(12,163 / 31,300,38.86 \%, 95 \%$ CI $38.32-39.40)$ to $44.35 \%$ $(18,190 / 41,014,44.35 \%, 95 \%$ CI $43.87-44.83, P<.001)$. Additionally, requiring a written duration resulted in a reduction in prescriptions where the calculated duration was longer than the written duration $(5617 / 31,300,17.95 \%, 95 \%$ CI 17.52-18.37, vs $6650 / 41,014,16.21 \%, 95 \%$ CI $15.86-16.57, P<.001)$. Changes in percentages of each relationship between written duration and calculated duration, pre- and postintervention, are presented in Table 2.

Table 2. Totals and percentages of each cohort and their associated relationships for pre- and postintervention.

\begin{tabular}{|c|c|c|c|c|}
\hline Relationship & Preperiod $(\mathrm{N}=31,300), \mathrm{n}(\%)$ & Postperiod $(\mathrm{N}=41,014), \mathrm{n}(\%)$ & $\begin{array}{l}P \text { val- } \\
\text { ue }\end{array}$ & Total $(\mathrm{N}=72,314), \mathrm{n}(\%)$ \\
\hline Calculated duration equal to written duration & $12,163(38.86)$ & $18,190(44.35)$ & $<.001$ & $30,353(41.97)$ \\
\hline Calculated duration less than written duration & $13,520(43.19)$ & $16,174(39.44)$ & $<.001$ & $29,694(41.06)$ \\
\hline Calculated duration greater than written duration & $5617(17.95)$ & $6650(16.21)$ & $<.001$ & $12,267(16.96)$ \\
\hline
\end{tabular}

\section{Discussion}

\section{Principal Findings}

The opioid epidemic is a major concern in the United States, specifically in the Commonwealth of Pennsylvania $[1,18]$ where the governor has issued a state emergency disaster declaration since 2018 [37]. Our hospitals and clinics are located in the heart of a major urban area within the state, in a county that hosts the highest estimated frequency of overdose deaths [38] and neighbors a district considered to be the epicenter for illicit opioid trade in the region [39].

In order to aid in many state-, city-, and hospital-level initiatives, our clinical informatics group has recently employed solutions to combat the opioid epidemic. These include simplifying PDMP queries, modifications of prescription settings in the emergency department, and analytics tools to track opioid prescribing throughout the institution [40,41].

Reduction in opioid prescriptions is a key step in combating this epidemic, and the duration of prescriptions has a significant effect on a patient's risk of becoming a chronic opioid user $[12,22]$.

In order to study our upcoming planned interventions, we realized we needed a reliable way to calculate durations of opioid prescriptions. Given the prior lack of requirement to document a written duration in our EHR system, we wanted to explore whether this was an accurate representation of a prescription's true duration and whether making this a requirement improved overall representation of the duration of a prescription as measured by the calculated duration.

Overall, written duration was equal to the calculated duration $(41.97 \%)$ or less than the calculated duration $(41.06 \%)$ the majority of the time. However, $16.96 \%$ of the time our prescriptions had a longer calculated duration than the written duration, which contradicts CDC prescribing guidelines. We are concerned that unintentionally prolonged opioid prescription durations could be contributing to an increased risk of opioid dependence. We must take this opportunity to stress that we do not imply that these prescriptions were intentionally written to break guidelines or to prolong a patient's duration of opioid therapy. We are simply stating that we observed a difference in these two values and we believe this requires attention. One solution to this issue could be modifications to the EHR system.

In order to provide peak levels of patient safety and end-user satisfaction, EHRs require continuous review and optimization. A lack of a required field allowed prescription durations to not match what the provider had documented, or likely intended. This is apparent in that requiring documentation of this field reduced those prescriptions without written durations, improved the percentage of written durations that accurately represented their corresponding calculated durations, and reduced the number of calculated durations that exceeded written durations. As discussed in our results, we explored the remaining $9.45 \%$ of prescriptions that continued to lack a written duration after our intervention and determined that they were likely due to renewals of prescriptions written prior to our modifications, where the system allows the field previously left blank to remain. Additionally, our intervention did yield a small but significant reduction in prescriptions where we were unable to compute a calculated duration $(6.01 \%$ vs $3.61 \%)$. We attribute this to the addition of a quick button, as described in our methods.

Many studies have demonstrated how modifications to CPOE can affect opioid prescribing, though most of the literature focuses on tablet counts and not duration of treatment. Delgado et al demonstrated that when transitioning from an EHR that had no preset dispense quantity to an EHR that required a preset of 10 tablets, the median number of oxycodone $5 \mathrm{mg} /$ acetaminophen $325 \mathrm{mg}$ tablets dispensed by two emergency departments decreased from 11.3 to 10.0 and from 12.6 to 10.9 , respectively [33]. Similarly, Chiu et al demonstrated that when opioids were prescribed at discharge for outpatient surgery, modification of the default pill count from 30 tablets to 12 tablets reduced the median number of tablets dispensed from 30 to 20 tablets [34]. However, they did not examine prescription duration, noting that duration guidelines are usually "far longer than most patients will need," and modifications of number of tablets dispensed will have a more profound affect [34]. While we believe reduction of tablets dispensed is critical to combating the opioid epidemic, at this time, CDC guidelines consider prescription duration to be an important measurement in reducing opioid therapy and combating the epidemic $[23,24]$. 
Conversely, other studies have demonstrated results from entirely removing presets for opioid tablets dispensed. Santistevan et al showed that in an emergency department setting, removal of the default of 20 tablets for hydrocodone and oxycodone, and the requirement of the prescriber to enter a number of tablets to dispense, reduced the median number of tablets prescribed from 20 to 15 [35]. The authors concluded that EHR presets may hinder providers' ability to prescribe opioids to appropriately fit the variability in patient care (ie, more painful clinical conditions need more tablets) and that prescriptions written at the provider's discretion may be more appropriate. Contrary to these results, Zwank et al demonstrated an increase in mean number of tablets from 15.31 to 15.77 after removing their 15-tablet preset and requiring manual entry of tablets dispensed [36].

Crothers et al also examined the effects of transitioning between EHR systems, from a homegrown system to a vendor-based system [42]. Their prior EHR system auto-calculated the maximum number of dispense units for PRN opioid prescriptions based on dose, frequency, and duration documented. During their implementation, they removed this functionality and instead developed preset dispense quantities, with outpatient prescriptions for clinics and inpatient discharges defaulted to 30 tablets for oxycodone and null for hydrocodone. This resulted in a decrease of 1.4 dispense units overall and 3.9 dispense units for inpatient discharge [42].

While these studies have examined the effect of changes in the requirement to document the number of tablets dispensed [33-36], to our knowledge we are the first to examine the requirement of documenting a duration field and comparing the duration intended by a prescriber (ie, written duration) to the calculated duration based on the number of tablets dispensed and instructions provided.

Our results confirm that simple documentation of an opioid prescription's duration is not sufficient. When a duration field is not directly linked to other elements of the prescription and there is no automated calculation of duration from dose, frequency, and quantity — or vice versa-inaccuracies remain. While it is interesting that Crothers et al demonstrated that removal of such functionality reduced opioid dispensing [42], this was performed during a transition of EHR systems and with the addition of prescription presets, which likely influenced their results. Given the importance of the duration of an opioid prescription in the associated risk of long-term use, as well as further potential for overdose, it is vital to have data that accurately represents this value. Additionally, we have demonstrated that retrospective computation of a calculated duration is a viable alternative when written durations are not available for the study of EHR prescribing data.

In order to improve compliance to CDC opioid prescribing guidelines, EHR system vendors should consider rapidly developing tools that, by default, accurately represent prescription durations and/or modify doses and quantities dispensed based on provider-entered durations. As described in the Introduction, this calculation already exists in our system, but no hard stop or passive updating of prescription fields exists. If a provider intends to prescribe one tablet, three times a day for 3 days, the system should automatically set the quantity at nine tablets; if the provider reduces the quantity to six tablets, the duration of the prescription should automatically be reduced to 2 days.

\section{Limitations}

Our study was performed at a single, urban academic institution and its associated ambulatory clinics; therefore, our results may not represent the majority of the country's hospitals. However, given that our institution is located in the state with the third-highest rate of drug overdose, our results may be valid when compared to other states of similar rates of overdose.

Additionally, as discussed in our methods, we intentionally biased our process of computing the calculated duration to make our resulting durations as short as possible by assuming individual doses were the higher of the possible range (ie, if a possible dose was 5-10 mg, we assumed the dose was $10 \mathrm{mg}$, thereby meaning that the quantity was used faster and the duration was shorter). This means that our calculations may underrepresent the number of prescriptions where the calculated duration was longer than the written duration if patients were to ration their medications and take lower doses over a longer period of time. Further, while our main intervention was making the duration field a requirement, we also added quick-action buttons and modified some prescription settings, which may have influenced our postperiod results, though we expect this to have been minimal. Finally, we used EHR data to represent durations of medications. While we believe it is important for our prescriptions to accurately represent the intended therapy and to abide by CDC guidelines, we did not determine whether individual patients took their prescribed medication as written, nor did we examine whether each prescription was filled at a pharmacy.

\section{Conclusions}

Accurate documentation of an opioid prescription's duration is critical, both for patient safety and for secondary use in analysis of the status of the opioid epidemic, as well as for evaluating interventions implemented to combat this public health crisis. Our study demonstrates that more than $17 \%$ of prescriptions written at our institution had durations documented in the EHRs that were shorter than durations calculated via the dose, frequency, and quantity of tablets prescribed. Requiring documentation of the duration field in a prescription improved these errors statistically but, clinically, a large number of prescriptions continued to not match the calculated duration. EHR vendors should invest in research and development to create functions that automatically calculate and fill values of the opioid prescription to ensure prescriptions are accurately represented, while physicians and hospitals should invest in informatics initiatives to study and improve provider-prescribing practices. 


\section{Acknowledgments}

Publication was made possible, in part, by support from the Thomas Jefferson University + Philadelphia University Open Access Fund.

\section{Conflicts of Interest}

None declared.

\section{References}

1. The Opioid Epidemic by the Numbers. Washington, DC: US Department of Health \& Human Services (HHS); 2019 Jan. URL: https://www.hhs.gov/opioids/sites/default/files/2019-09/opioids-infographic.pdf [accessed 2020-01-27]

2. Rudd RA, Seth P, David F, Scholl L. Increases in drug and opioid-involved overdose deaths: United States, $2010-2015$. MMWR Morb Mortal Wkly Rep 2016 Dec 30;65(50-51):1445-1452 [FREE Full text] [doi: 10.15585/mmwr.mm655051e1] [Medline: 28033313]

3. Scholl L, Seth P, Kariisa M, Wilson N, Baldwin G. Drug and opioid-involved overdose deaths: United States, $2013-2017$. MMWR Morb Mortal Wkly Rep 2018 Jan 04;67(5152):1419-1427 [FREE Full text] [doi: 10.15585/mmwr.mm675152e1] [Medline: $\underline{30605448}$ ]

4. Katz J. The New York Times. 2017. Drug deaths in America are rising faster than ever URL: https://www.nytimes.com/ interactive/2017/06/05/upshot/opioid-epidemic-drug-overdose-deaths-are-rising-faster-than-ever.html [accessed 2017-08-19]

5. Kuehn BM. Alarming nonfatal overdose rates found for opioids, sedatives, and tranquilizers. JAMA 2010 May 26;303(20):2020-2021. [doi: 10.1001/jama.2010.641] [Medline: 20501919]

6. Coben JH, Davis SM, Furbee PM, Sikora RD, Tillotson RD, Bossarte RM. Hospitalizations for poisoning by prescription opioids, sedatives, and tranquilizers. Am J Prev Med 2010 May;38(5):517-524. [doi: 10.1016/j.amepre.2010.01.022] [Medline: 20409500]

7. Dunn KM, Saunders KW, Rutter CM, Banta-Green CJ, Merrill JO, Sullivan MD, et al. Opioid prescriptions for chronic pain and overdose: A cohort study. Ann Intern Med 2010 Jan 19;152(2):85-92 [FREE Full text] [doi: 10.7326/0003-4819-152-2-201001190-00006] [Medline: 20083827]

8. Coffin PO, Galea S, Ahern J, Leon AC, Vlahov D, Tardiff K. Opiates, cocaine and alcohol combinations in accidental drug overdose deaths in New York City, 1990-98. Addiction 2003 Jun;98(6):739-747. [doi: 10.1046/j.1360-0443.2003.00376.x] [Medline: 12780362]

9. Darke S. Oxycodone poisoning: Not just the 'usual suspects'. Addiction 2011 Jun;106(6):1035-1036. [doi: 10.1111/j.1360-0443.2011.03395.x] [Medline: 21564365]

10. Häkkinen M, Launiainen T, Vuori E, Ojanperä I. Comparison of fatal poisonings by prescription opioids. Forensic Sci Int 2012 Oct 10;222(1-3):327-331. [doi: 10.1016/j.forsciint.2012.07.011] [Medline: 22884575]

11. Hall AJ, Logan JE, Toblin RL, Kaplan JA, Kraner JC, Bixler D, et al. Patterns of abuse among unintentional pharmaceutical overdose fatalities. JAMA 2008 Dec 10;300(22):2613-2620. [doi: 10.1001/jama.2008.802] [Medline: 19066381]

12. Edlund MJ, Martin BC, Russo JE, DeVries A, Braden JB, Sullivan MD. The role of opioid prescription in incident opioid abuse and dependence among individuals with chronic noncancer pain: The role of opioid prescription. Clin J Pain 2014 Jul;30(7):557-564 [FREE Full text] [doi: 10.1097/AJP.0000000000000021] [Medline: 24281273]

13. Jones CM. Heroin use and heroin use risk behaviors among nonmedical users of prescription opioid pain relievers: United States, 2002-2004 and 2008-2010. Drug Alcohol Depend 2013 Sep 01;132(1-2):95-100. [doi:

10.1016/j.drugalcdep.2013.01.007] [Medline: 23410617]

14. Gaither JR, Leventhal JM, Ryan SA, Camenga DR. National trends in hospitalizations for opioid poisonings among children and adolescents, 1997 to 2012. JAMA Pediatr 2016 Dec 01;170(12):1195-1201. [doi: 10.1001/jamapediatrics.2016.2154] [Medline: 27802492]

15. Nuckols TK, Anderson L, Popescu I, Diamant AL, Doyle B, Di Capua P, et al. Opioid prescribing: A systematic review and critical appraisal of guidelines for chronic pain. Ann Intern Med 2014 Jan 07;160(1):38-47 [FREE Full text] [doi: 10.7326/0003-4819-160-1-201401070-00732] [Medline: 24217469]

16. United States Census Bureau. 2020. US and world population clock URL: https://www.census.gov/popclock/ [accessed 2020-01-27]

17. Gusovsky D. CNBC. 2016 Apr 27. Americans consume vast majority of the world's opioids URL: https://www.cnbc.com/ 2016/04/27/americans-consume-almost-all-of-the-global-opioid-supply.html [accessed 2019-09-04]

18. DEA Philadelphia Division, University of Pittsburgh. The Opioid Threat in Pennsylvania. Arlington, VA: United States Drug Enforcement Administration; 2018 Sep. URL: https://www.dea.gov/sites/default/files/2018-10/PA\%200pioid\%20 Report\%20Final\%20FINAL.pdf [accessed 2019-09-04]

19. Centers for Disease Control and Prevention. 2019 Jan 10. Drug overdose mortality by state URL: $\underline{\text { https://www.cdc.gov/ }}$ nchs/pressroom/sosmap/drug poisoning mortality/drug poisoning.htm [accessed 2019-06-26]

20. Griggs CA, Weiner SG, Feldman JA. Prescription drug monitoring programs: Examining limitations and future approaches. West J Emerg Med 2015 Jan;16(1):67-70 [FREE Full text] [doi: 10.5811/westjem.2014.10.24197] [Medline: 25671011] 
21. Bohnert AS, Valenstein M, Bair MJ, Ganoczy D, McCarthy JF, Ilgen MA, et al. Association between opioid prescribing patterns and opioid overdose-related deaths. JAMA 2011 Apr 06;305(13):1315-1321. [doi: 10.1001/jama.2011.370] [Medline: 21467284]

22. Shah A, Hayes CJ, Martin BC. Characteristics of initial prescription episodes and likelihood of long-term opioid use: United States, 2006-2015. MMWR Morb Mortal Wkly Rep 2017 Mar 17;66(10):265-269 [FREE Full text] [doi:

10.15585/mmwr.mm6610a1] [Medline: 28301454]

23. Dowell D, Haegerich TM, Chou R. CDC guideline for prescribing opioids for chronic pain: United States, 2016. JAMA 2016 Apr 19;315(15):1624-1645 [FREE Full text] [doi: 10.1001/jama.2016.1464] [Medline: 26977696]

24. Dowell D, Haegerich TM, Chou R. CDC guideline for prescribing opioids for chronic pain: United States, 2016. MMWR Recomm Rep 2016 Mar 18;65(1):1-49. [doi: 10.15585/mmwr.rr6501e1] [Medline: 26987082]

25. Han B, Compton WM, Blanco C, Crane E, Lee J, Jones CM. Prescription opioid use, misuse, and use disorders in US adults: 2015 National Survey on Drug Use and Health. Ann Intern Med 2017 Sep 05;167(5):293-301. [doi: 10.7326/M17-0865] [Medline: 28761945]

26. Chaudhry B, Wang J, Wu S, Maglione M, Mojica W, Roth E, et al. Systematic review: Impact of health information technology on quality, efficiency, and costs of medical care. Ann Intern Med 2006 May 16;144(10):742-752. [doi: 10.7326/0003-4819-144-10-200605160-00125] [Medline: 16702590]

27. Erstad TL. Analyzing computer based patient records: A review of literature. J Healthc Inf Manag 2003;17(4):51-57. [Medline: 14558372]

28. Menachemi N, Brooks RG. Reviewing the benefits and costs of electronic health records and associated patient safety technologies. J Med Syst 2006 Jun;30(3):159-168. [doi: 10.1007/s10916-005-7988-x] [Medline: 16848129]

29. Wang SJ, Middleton B, Prosser LA, Bardon CG, Spurr CD, Carchidi PJ, et al. A cost-benefit analysis of electronic medical records in primary care. Am J Med 2003 Apr 01;114(5):397-403. [doi: 10.1016/s0002-9343(03)00057-3] [Medline: $\underline{12714130]}$

30. Menachemi N, Collum TH. Benefits and drawbacks of electronic health record systems. Risk Manag Healthc Policy 2011;4:47-55 [FREE Full text] [doi: 10.2147/RMHP.S12985] [Medline: 22312227]

31. Tolley CL, Slight SP, Husband AK, Watson N, Bates DW. Improving medication-related clinical decision support. Am J Health Syst Pharm 2018 Feb 15;75(4):239-246. [doi: 10.2146/ajhp160830] [Medline: 29436470]

32. Wen H, Hockenberry JM, Jeng PJ, Bao Y. Prescription drug monitoring program mandates: Impact on opioid prescribing and related hospital use. Health Aff (Millwood) 2019 Sep;38(9):1550-1556. [doi: 10.1377/hlthaff.2019.00103] [Medline: $\underline{31479368]}$

33. Delgado MK, Shofer FS, Patel MS, Halpern S, Edwards C, Meisel ZF, et al. Association between electronic medical record implementation of default opioid prescription quantities and prescribing behavior in two emergency departments. J Gen Intern Med 2018 Apr;33(4):409-411 [FREE Full text] [doi: 10.1007/s11606-017-4286-5] [Medline: 29340937]

34. Chiu AS, Jean RA, Hoag JR, Freedman-Weiss M, Healy JM, Pei KY. Association of lowering default pill counts in electronic medical record systems with postoperative opioid prescribing. JAMA Surg 2018 Nov 01;153(11):1012-1019 [FREE Full text] [doi: 10.1001/jamasurg.2018.2083] [Medline: $\underline{30027289}$ ]

35. Santistevan JR, Sharp BR, Hamedani AG, Fruhan S, Lee AW, Patterson BW. By default: The effect of prepopulated prescription quantities on opioid prescribing in the emergency department. West J Emerg Med 2018 Mar;19(2):392-397 [FREE Full text] [doi: 10.5811/westjem.2017.10.33798] [Medline: 29560071]

36. Zwank MD, Kennedy SM, Stuck LH, Gordon BD. Removing default dispense quantity from opioid prescriptions in the electronic medical record. Am J Emerg Med 2017 Oct;35(10):1567-1569. [doi: 10.1016/j.ajem.2017.04.002] [Medline: $\underline{28416266]}$

37. Wolf T. Proclamation: Amendment to Proclamation of Disaster Emergency. Harrisburg, PA: Commonwealth of Pennsylvania, Office of the Governor; 2019 Mar 20. URL: https://www.governor.pa.gov/wp-content/uploads/2019/03/20190320-opioiddisaster-emergency-renual.pdf [accessed 2019-09-04]

38. OpenDataPA, Commonwealth of Pennsylvania. 2019 Jul 19. Estimated accidental and undetermined drug overdose deaths CY 2017-2018: County Health URL: https://data.pa.gov/Opioid-Related/ Estimated-Accidental-and-Undetermined-Drug-Overdos/azzc-q64m [accessed 2020-01-27]

39. Percy J. The New York Times Magazine. 2018 Oct 10. Trapped by the 'Walmart of Heroin' URL: https://www.nytimes.com/ 2018/10/10/magazine/kensington-heroin-opioid-philadelphia.html [accessed 2019-09-04]

40. Slovis B, London K, Randolph F, Aini M, Mammen P, Martino C, et al. The effect of implementing electronic health record default prescribing preferences on opioid prescriptions written in the emergency department. Ann Emerg Med 2018 Oct;72(4, Supplement):S133 [FREE Full text] [doi: 10.1016/j.annemergmed.2018.08.341]

41. Martino C. Upshot. 2018 Jul 09. Fighting the opioid epidemic with the right people and the right tools URL: https:/ /upshotstories.com/stories/fighting-the-opioid-epidemic-with-the-right-people-and-the-right-tools [accessed 2019-09-04]

42. Crothers G, Edwards DA, Ehrenfeld JM, Woo E, McCluggage L, Lobo B. Evaluating the impact of auto-calculation settings on opioid prescribing at an academic medical center. Jt Comm J Qual Patient Saf 2019 Jun;45(6):416-422. [doi: 10.1016/j.jcjq.2019.02.010] [Medline: 30935884] 


\title{
Abbreviations
}

CDC: US Centers for Disease Control and Prevention

CPOE: computerized provider order entry

EHR: electronic health record

PDMP: prescription drug monitoring program

PRN: pro re nata

\author{
Edited by J Hefner; submitted 09.09.19; peer-reviewed by C Fincham, C Sieck, D Wong; comments to author 02.10.19; revised version \\ received 24.11.19; accepted 14.01.20; published 31.03.20 \\ Please cite as: \\ Slovis BH, Kairys J, Babula B, Girondo M, Martino C, Roke LM, Riggio J \\ Discrepancies in Written Versus Calculated Durations in Opioid Prescriptions: Pre-Post Study \\ JMIR Med Inform 2020;8(3):e16199 \\ URL: https://medinform.jmir.org/2020/3/e16199 \\ doi: $\underline{10.2196 / 16199}$ \\ PMID: 32229472
}

(CBenjamin H Slovis, John Kairys, Bracken Babula, Melanie Girondo, Cara Martino, Lindsey M Roke, Jeffrey Riggio. Originally published in JMIR Medical Informatics (http://medinform.jmir.org), 31.03.2020. This is an open-access article distributed under the terms of the Creative Commons Attribution License (https://creativecommons.org/licenses/by/4.0/), which permits unrestricted use, distribution, and reproduction in any medium, provided the original work, first published in JMIR Medical Informatics, is properly cited. The complete bibliographic information, a link to the original publication on http://medinform.jmir.org/, as well as this copyright and license information must be included. 